\title{
En mann med invalidiserende ortostatisk hypotensjon
}

\begin{abstract}
Kombinasjonen ortostatisk hypotensjon og hypertensjon kan være vanskelig å håndtere. Etter ti år med uttalt hypertensjon og betydelige bivirkninger av blodtrykkssenkende medisiner ble pasientens symptomer og blodtrykk drastisk redusert ved at hodeenden på sengen ble hevet.
\end{abstract}

Video på www.tidsskriftet.no

Se kommentar side 1762

\author{
Kristian Bernhard Nilsen \\ kristian.b.nilsen@ntnu.no \\ Seksjon for klinisk nevrofysiologi \\ Nevrologisk avdeling \\ Oslo universitetssykehus, Ullevål \\ og \\ Institutt for nevromedisin \\ Pål Berg-Hansen \\ Nevrologisk avdeling \\ Oslo universitetssykehus, Ullevål

\section{Eivind Berge} \\ Kardiologisk avdeling \\ Oslo universitetssykehus, Ullevål

\section{Mette Ajer Petterson} \\ Abildsø legekontor \\ Knut Gjesdal \\ Kardiologisk avdeling \\ Oslo universitetssykehus, Ullevål \\ og \\ Institutt for klinisk medisin \\ Universitetet i Oslo
}

Norges teknisk-naturvitenskapelige universitet

En mann i 60-årene ble innlagt i sykehus for utredning av svimmelhet $i$ stående stilling. Han hadde $i$ ett år vært behandlet for hypertensjon med angiotensinreseptorblokkeren losartan i kombinasjon med hydroklortiazid. I løpet av de fem foregående månedene hadde han gjennomgått aortokoronar bypassoperasjon og operasjon for torakoabdominalt aortaaneurisme. I forbindelse med bypassoperasjonen ble det startet med betablokkeren metoprolol $100 \mathrm{mg} \times 1$ og kalsiumkanalblokkeren amlodipin $5 \mathrm{mg} \times 1$ grunnet hypertensjon opp mot 200/85 mm Hg målt preoperativt. Blodtrykket i liggende stilling ble nå målt til 170/100 mm Hg. Etter ett minutt i stående stilling ble pasienten svimmel og måtte sette seg. Blodtrykket var da $95 / 60 \mathrm{~mm} \mathrm{Hg}$.

Plagene ble ansett som bivirkninger av antihypertensivene. Disse ble seponert og pasienten utskrevet med fludrokortisonacetat $0,1 \mathrm{mg} \times 1$. Han hadde imidlertid stadig hypertensjon ved kontroll hos fastlegen. Fludrokortisonacetat ble etter hvert seponert, og etter tre måneder fikk han angiotensinreseptorblokkeren losartan.
Pasienten hadde en symptomgivende ortostatisk hypotensjon, med en reduksjon i systolisk blodtrykk på $75 \mathrm{~mm} \mathrm{Hg}$ fra liggende til stående stilling. Ortostatisk hypotensjon defineres som en reduksjon i systolisk blodtrykk på minst $20 \mathrm{~mm} \mathrm{Hg}$ (ev. reduksjon $\mathrm{i}$ diastolisk blodtrykk på minst $10 \mathrm{~mm} \mathrm{Hg}$ ) innen tre minutter etter overgang til stående stilling (eller vipping til minst $\left.60^{\circ}\right)(1,2)$. Ortostatisk hypotensjon er strengt tatt bare et funn, men når det er symptomgivende, anses det også som en diagnose. Blodtrykkssenkende medisiner er en vanlig årsak (3). Ortostatisk hypotensjon øker i hyppighet med stigende alder og kan ha både kardiale (f.eks. aortastenose) og nevrogene årsaker (f.eks. nevropati).

Pasienten ble seks år senere på nytt henvist til sykehus på grunn av svimmelhet i stående stilling. Like før konsultasjonen hadde han et bevissthetstap uten kramper. Til tross for stadig progredierende symptomer hadde han akseptert plagene og forsøkt å tilpasse seg situasjonen. Han brukte metoprolol $50 \mathrm{mg} \times 1$ som eneste blodtrykkssenkende medisin. 24timers EKG-registrering viste normofrekvent sinusrytme uten bradykardiepisoder. Blodtrykket ble målt til 180/100 mm Hg i sittende stilling og til 130/80 mm Hg stående (tid mellom målingene ikke angitt).

Kortvarig bevissthetstap kan ha mange årsaker. Anamnesen er viktig for å skille mellom ulike årsaker, som synkope, epilepsi, traume og hjerneslag. Bevissthetstap som et resultat av kortvarig global cerebral hypoperfusjon betegnes synkope (4). Synkope har akutt debut, kort varighet og spontan fullstendig gjenvinning av bevisstheten. Denne definisjonen er internasjonalt anerkjent og innebærer at synkope er én av flere årsaker til bevissthetstap. En kardial synkope (arytmi, alvorlig aortastenose) kan varsle potensielt livstruende hjertearytmier, og ved anamnestiske holdepunkter for hjertesykdom hos pasienten eller nære slektninger er rask og omfattende utredning nødvendig. Ved negativ hjerteanamnese er det som regel tilstrekkelig med auskultasjon etter bilyd, 12-kanals-EKG samt (hos dem over 40 år) test av carotisrefleks med massasje av sinus caroticus under overvåking av hjerterytme og blodtrykk (ikke ved kontraindikasjoner som stenoselyd). 24-timers-EKG kan være indisert i noen tilfeller (5). Det kan være hvis pasienten har følt urolig hjerte, ved uvanlig langsom eller rask puls, tidligere arytmier eller ved besvimelse i sittende eller liggende stilling. Synkope kan også skyldes ortostatisk hypotensjon eller vasovagale reaksjoner.

Både bevissthetstapet og symptomene $i$ stående stilling ble igjen tilskrevet ortostatisk hypotensjon. Fordi pasienten hadde uttalt hypertensjon i liggende stilling, ble det ikke gjort endringer i medikasjonen. Han ble anbefalt å unngå å bli stående oppreist og heller sette seg eller være i bevegelse.

Et år senere fikk han økende vanskeligheter med å komme seg ut av sengen. Han gikk langsommere enn før, brukte lang tid på å kle på seg, følte at han hadde økende balanseproblemer og falt flere ganger. Han ble henvist til privatpraktiserende nevrolog, som fant at pasienten, som nå var i 70-årene, var kognitivt upåfallende, men snakket med monoton stemme. Han hadde brady- og hypokinesi ved test av finmotoriske evner samt rigiditet ved test av tonus, i tillegg til nedsatt spontan ansiktsmimikk og lett fremoverbøyd holdning med nedsatt medbevegelse av høyre arm under gange. Han hadde ikke hviletremor, det var sidelike reflekser og plantarrefleksen var nedadvendt bilateralt. Flere familiemedlemmer på morssiden skulle ha vært plaget med skjelving på hendene, og to andre familiemedlemmer skulle ha fått diagnosen Parkinsons sykdom.

Bradykinesi (langsomme bevegelser) og hypokinesi (nedsatt evne til å utføre voluntære bevegelser) ved test av finmotorikk er kardinaltegn på parkinsonisme. I tillegg kommer rigiditet ved test av muskeltonus og en (ikke obligatorisk) hviletremor. En parkinsonisme betegnes ofte som enten tremordominant eller av akinetisk/rigid type. Tilstanden er typisk for Parkinsons sykdom, men ses også ved en rekke andre nevrodegenerative lidelser, som multisystematrofi (MSA), progredierende supranukleær parese (PSP) og kortikobasal degenerasjon. I tillegg kan parkinsonisme være medikamentelt betinget eller et resultat av subkortikale iskemiske forandringer. Parkinsonisme uten hviletremor er vanligere når tilstanden ikke skyldes Parkin- 
sons sykdom (6). Opptil $20 \%$ av dem med Parkinsons sykdom har nære slektninger med sykdommen. Man kan være genetisk predisponert, men genfeil alene gir kun i sjeldne tilfeller Parkinsons sykdom (7). Den har ofte en asymmetrisk debut.

Pasientens aktuelle symptomer ble oppfattet som forenlige med Parkinsons sykdom, og det ble startet med dopaminerg medikasjon.

Få måneder etter konsultasjonen hos nevrolog ble pasienten lagt inn $i$ sykehus grunnet hyppige bevissthetstap og fall. Det kom frem at han hadde hatt bevissthetstap ukentlig de siste 8-10 månedene, og at disse var blitt hyppigere og opptrådte nærmest daglig etter at han startet med dopaminerg medikasjon. Hans parkinsonistiske symptomer var uendret. Det kom også frem at han hadde hatt ereksjonssvikt i fem år samt nokturi $\times$ 2-3 som ikke var nærmere utredet. EKG og telemetri viste sinusrytme med enkelte supraventrikulære ekstrasystoler, men uten pauser eller blokkeringer. Det ble utført nevrofysiologisk testing av det autonome nervesystemet med vippetest med kontinuerlig blodtrykksmåling (fig 1), måling av hjertefrekvensvariabilitet under dyp respirasjon og måling av kardiovaskulær respons på Valsalvas manøver (fig 2). Under vippetesten falt det systoliske blodtrykket med $98 \mathrm{~mm} \mathrm{Hg}$ etter ett minutt, og før det var gått tre minutter, måtte testen avbrytes grunnet ubehag. Det var ingen synlig hjertefrekvensvariabilitet ved dyp respirasjon, og blodtrykksfallet ved Valsalvas manøver var patologisk forlenget. Blodtrykket i liggende stilling var 186/85 mm Hg. MR caput viste diffust utbredt substanstap og spredte iskemiske forandringer.

Parkinsonisme og samtidig autonom svikt ved diagnosetidspunktet, eventuelt med autonom svikt før debut av parkinsonisme, er typisk for multisystematrofi. Pasienter med multisystematrofi har som oftest dårlig respons på dopaminerg medikasjon. Gjennomsnittlig debutalder er 57 år (8). Utviklingen av symptomene, den dårlige effekten av dopaminerg medikasjon og funnene ved testing av det autonome nervesystemet pekte nå i retning av multisystematrofi. Imidlertid kan det innvendes at familiemedlemmer med parkinsonisme, relativt høy alder ved diagnosetidspunktet ( $<75$ år) og den langsomme progredieringen gjorde diagnosen usikker. Vaskulær parkinsonisme var en aktuell differensialdiagnose. MR-forandringene trakk imidlertid mest $\mathrm{i}$ retning av en primær nevrodegenerasjon.

Det ble utført ny vippetest, denne gangen før og etter et standardisert energirikt måltid. Pasienten fikk betydelig økt ortostatisk blodtrykksreduksjon etter inntak av mat. Reduksjonen i systolisk blodtrykk etter ett minutt var $50 \mathrm{~mm} \mathrm{Hg}$ mer uttalt etter måltidet sammenliknet med da vippetesten ble

a

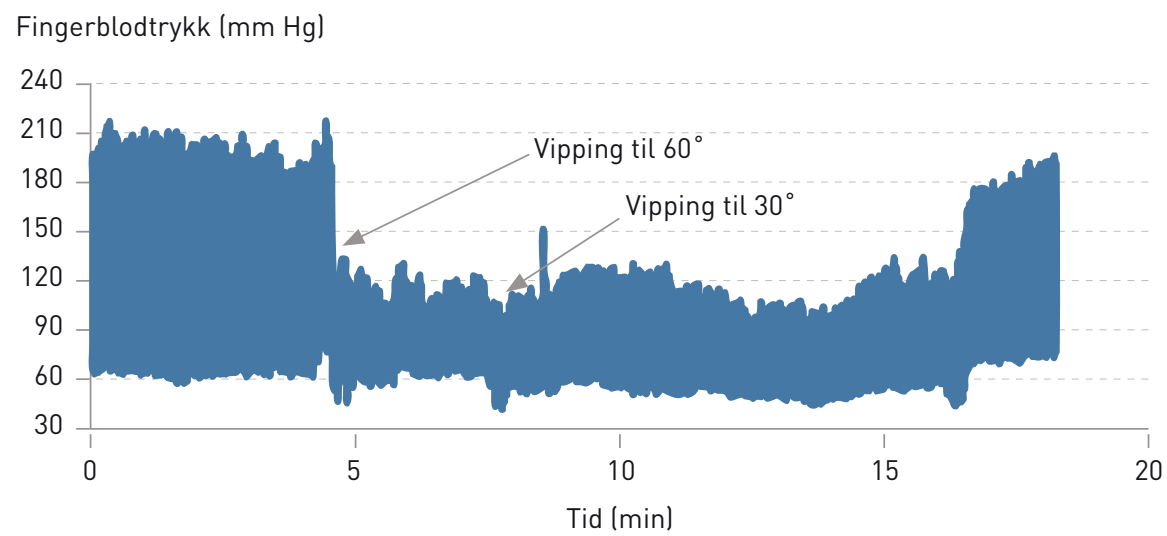

b

Systolisk blodtrykk (mm Hg)

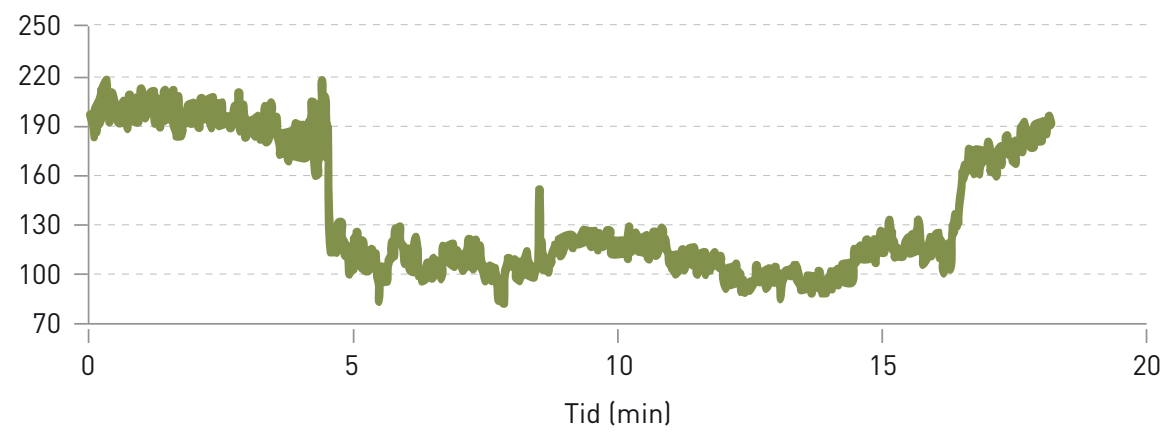

Hjertefrekvens (slag/min)

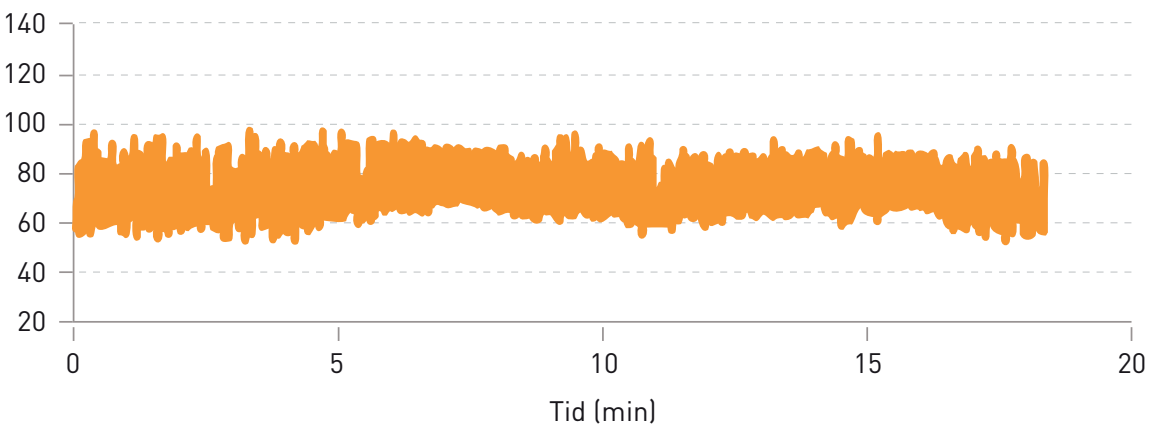

Figur 1 Kontinuerlig blodtrykksmåling under vippetest. Blodtrykket faller umiddelbart ved start av vipping og stiger umiddelbart når pasienten vippes tilbake til liggende stilling etter ti minutter. a) Blodtrykket målt med fingermansjett, b) avledet systolisk blodtrykk, c) hjertefrekvensen. Pasienten fikk ved vipping til $60^{\circ}$ umiddelbart et betydelig blodtrykksfall, mens hjertefrekvensen var stabil. Grunnet uttalte symptomer ble pasienten vippet ned til $30^{\circ}$ grader etter tre minutter

utført i fastende tilstand. Det ble også utført 24-timers blodtrykksmåling. Blodtrykket var markant høyere om natten enn om dagen lom natten 163/83 mm Hg, om dagen 150/79 $\mathrm{mm} \mathrm{Hg}$ ). Etter heving av hodeenden av sengen $10^{\circ}$ var blodtrykket fortsatt høyest om natten, men klart lavere både om natten og om dagen lom natten $150 / 82 \mathrm{~mm} \mathrm{Hg}$, om dagen 133/76 mm Hg).

Forverring av ortostatiske symptomer etter måltider er vanlig hos pasienter med nevro- gen ortostatisk hypotensjon (9). Det er også vanlig, men lite kjent, at pasientene har hypertensjon i liggende stilling $(10,11)$. Det har vært anbefalt å heve sengens hodeende for å motvirke dette (3).

Blodtrykksenkende og dopaminerg medikasjon ble seponert, og pasienten fikk råd om å drikke mer vann, spise hyppigere, bruke støttestrømper samt heve sengens hodeende. Ved kontroll etter henholdsvis en måned og ett år var pasienten mindre plaget med orto- 
Fingerblodtrykk $(\mathrm{mm} \mathrm{Hg}$ )

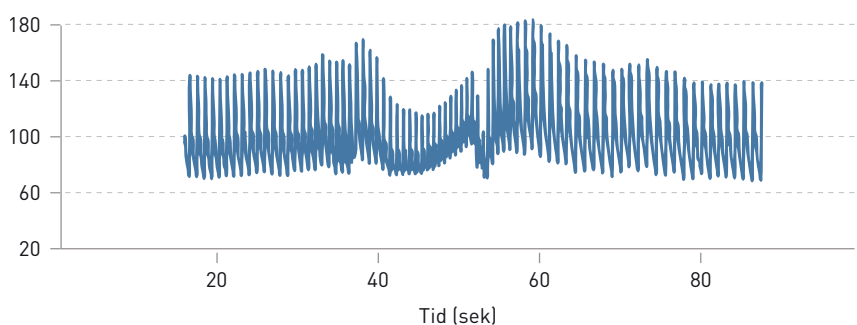

Systolisk blodtrykk (mm Hg)

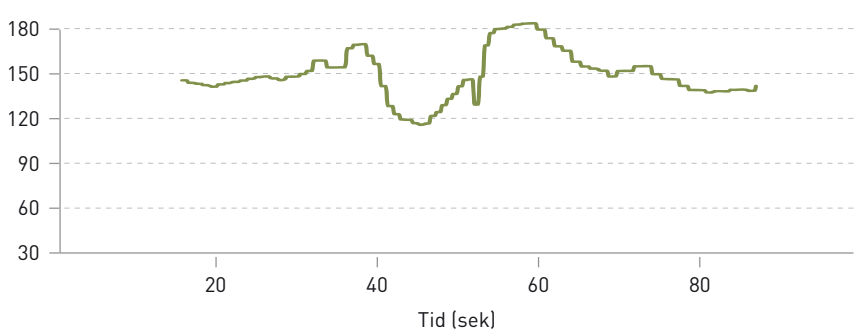

Hjertefrekvens (slag/min

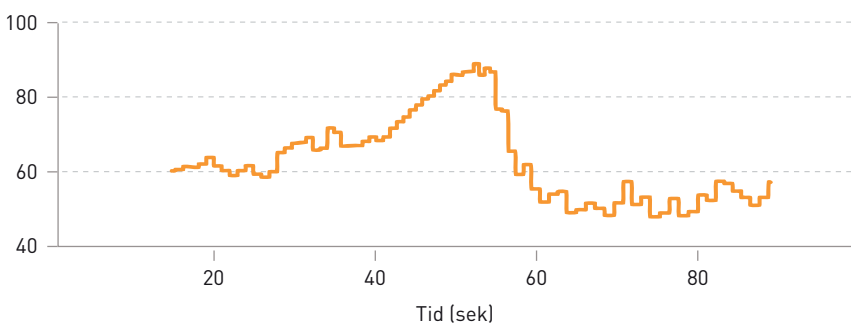

g

Valsalvatrykk $(\mathrm{mm} \mathrm{Hg})$

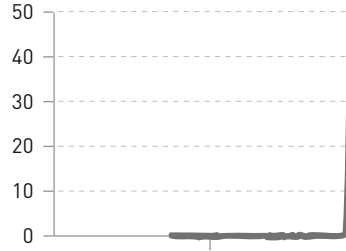

20

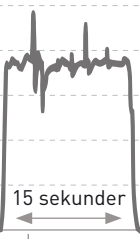

40

$$
\text { Tid (sek) }
$$

Fingerblodtrykk (mm Hg)

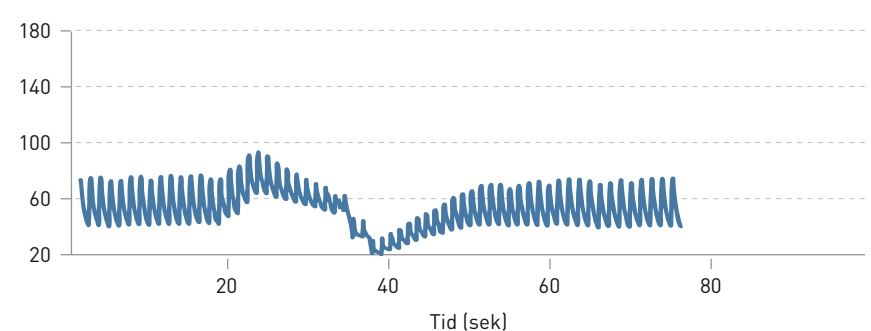

Systolisk blodtrykk (mm Hg)

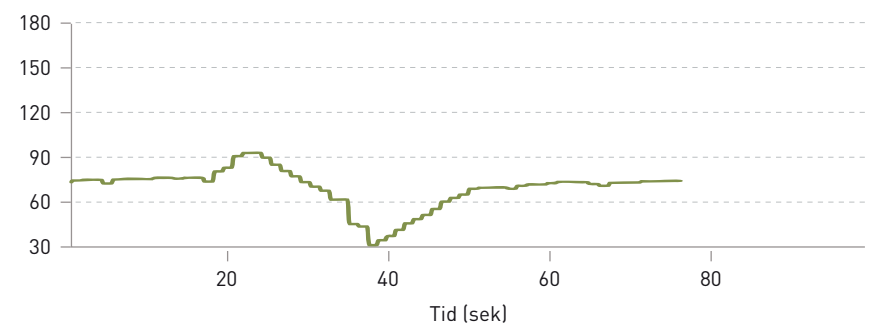

Hjertefrekvens (slag/min)

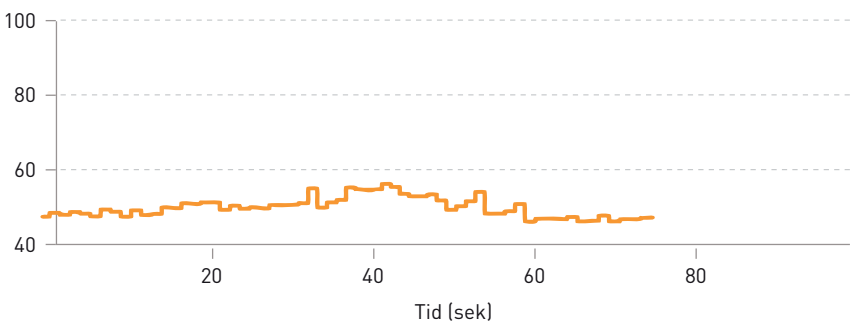

Valsalvatrykk (mm Hg)

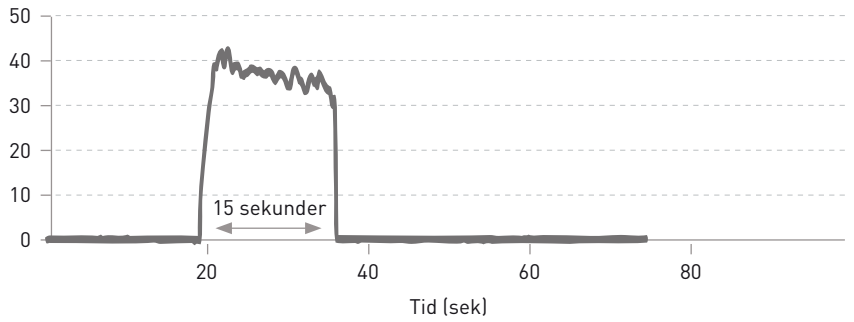

Figur 2 a-h) Kontinuerlig blodtrykksmåling under Valsalvas manøver. Valsalvas manøver utføres ved å presse luft ut av lungene mot et (nesten) tett munnstykke med en kraft på 40 mm Hg i 15 sekunder. Dette trykket vises i nederste rad (g og h). a og c) En normal blodtrykksrespons på Valsalvas manøver, b og d) en patologisk blodtrykksrespons på Valsalvas manøver, med manglende økning av blodtrykket i siste del av manøveren og manglende overkompensasjon i sekundene etter at manøveren er avsluttet. e) En normalog fl en patologisk lav hjertefrekvensrespons på Valsalvas manøver

statisk hypotensjon og hadde ingen flere synkoper. Det kom frem at han allerede fem år før første sykehusinnleggelse for utredning av svimmelhet, og før oppstart av blodtrykkssenkende medisiner, hadde hatt nærsynkoper ved korte stopp under spaserturer.

I ettertid fremstår pasientens plager som en langsomt progredierende autonom svikt (over mer enn ti år). Den langsomme progredieringen er noe uvanlig for multisystematrofi og minner mer om utviklingen man ser ved ren autonom svikt (pure autonomic failure, PAF) som har en bedre prognose. Pasienten ble vurdert ved ulike sykehus, ved ulike avdelinger og av leger med ulik bakgrunn og erfaring, hvilket kan ha bidratt til den sene diagnosen. Andre forklaringer på hyppige synkoper, som øt vasovagal refleks, arytmier, strukturelle kardiale sykdommer, venøs oppsamling av blod eller redusert blodvolum, var utelukket eller lite sannsynlig. Den diagnostiske usik- kerheten er imidlertid til å leve med i dette tilfellet, idet det ikke har noen konsekvenser for behandlingen.

\section{Diskusjon}

Multisystematrofi er tidligere beskrevet i Tidsskriftet (6). Sikker diagnose stilles post mortem, men kriterier for sannsynlig multisystematrofi er: Autonom svikt med enten urininkontinens (og erektil dysfunksjon) eller symptomgivende ortostatisk hypotensjon 
med et fall i systolisk blodtrykk på minst $30 \mathrm{~mm} \mathrm{Hg}$ (eller $15 \mathrm{~mm} \mathrm{Hg}$ diastolisk) innen tre minutter etter overgang til stående stilling. I tillegg finnes enten parkinsonisme med dårlig respons på levodopa eller cerebellær dysfunksjon (12). Nye konsensusbaserte diagnostiske kriterier ble publisert i 2008 (12). Multisystematrofi omfatter tilstander som tidligere var kjent som striatonigral degenerasjon, sporadisk olivopontocerebellær atrofi og Shy-Drägers syndrom. Det er to fenotypiske varianter - en parkinsonistisk (MSA-P) og en cerebellær (MSA-C). Enkelte pasienter kan ha elementer av begge variantene. Det finnes ingen kjente familiære tilfeller av multisystematrofi. Diagnosen settes ut fra kliniske karakteristika, eventuelt sammenholdt med resultatene av nevrofysiologisk testing av det autonome nervesystemet og bildefremstilling av hjernen.

Endelig diagnose baseres på nevropatologiske funn av alfasynukleinimmunreaktive inklusjoner i cytoplasma på oliogodendrocytter (gliaceller). Diagnosen krever at det ikke skal være et stort antall lewylegemer, i motsetning til differensialdiagnosene Parkinsons sykdom, ren autonom svikt og demens med lewylegemer, hvor det er særpregede inklusjoner (lewylegemer) i cytoplasma i nevroner i hjernen eller i perifere autonome nevroner (ved ren autonom svikt). Et forvirrende element er at inklusjonene man finner i alle disse tilstandene, både med og uten lewylegemer, inneholder proteinet alfasynuklein. Av den grunn brukes «autonom alfasynukleinopati» som en sekkebetegnelse for disse.

Det finnes målemetoder for de ulike autonome funksjoner, som kardiovaskulær respons på dyp respirasjon, endret leie (eksempelvis fra liggende til stående stilling) eller Valsalvas manøver. Måling av pupillresponser, svettefunksjon samt urodynamiske eller gastrodynamiske responser er andre muligheter. En screeningundersøkelse for autonom svikt kan innebære kontinuerlig blodtrykksmåling og EKG under dyp respirasjon, Valsalvas manøver og vippetest (fra liggende til $60^{\circ}$ ). Disse tre undersøkelsene kan avdekke kardiovagal (parasympatisk) og/eller sympatonevral svikt (sympatikussvikt). Aktuelle tilleggsundersøkelser er vippetest etter provokasjon med karbohydratrikt måltid, 24-timers blodtrykksmåling og måling av svettefunksjonen.

Plager med ortostatisk hypotensjon kan øke etter måltidene. Dette antas å skyldes manglende kompensatorisk sympatisk vasokonstriksjon etter den redistribusjonen av blod til tarmene som normalt skjer etter at man har spist. Karbohydratrike måltider gir mer hypotensjon enn fettrike (13).

Ortostatisk hypotensjon skyldes som regel venøs oppsamling av blod i bein og buk. Venene kan magasinere mer blod, enten fordi det er klaffeinsuffisiens, eller fordi de ikke konstringerer fordi sympatikusresponsen på blodtrykksfallet uteblir. Klaffeinsuffisiens kan behandles kirurgisk. Manglende venekon- striksjon kan motvirkes ved å bruke leggmuskelpumpen (gardistknepet). Målsydd strømpebukse gir ofte nyttig kompresjon. Rikelig drikke og salttabletter kan forsøkes hvis det ikke er hypertensjon i liggende stilling $(3,14)$, men denne behandlingen krever tett oppfølging. Aktuelle medikamenter er den alfa-1-adrenerge reseptorstimulatoren midodrine, natriumretinerende fludrokortisonacetat, eventuelt prostaglandinsyntasehemmeren indometacin $(3,14)$. Midodrine fås kun på registreringsfritak i Norge. Medikamentet øker både liggende og stående blodtrykk hos pasienter med nevrogen ortostatisk hypotensjon (15). Imidlertid foreligger det fremdeles ikke langtidsstudier av klinisk nytteverdi, slik det var forutsatt ved godkjenningen av medikamentet i 1996. Det har vært foreslått å trekke tilbake godkjenningen.

Ortostatisk hypotensjon kan ses ved nevrodegenerative tilstander som affiserer områder $\mathrm{i}$ sentralnervesystemet som regulerer det autonome nervesystemet (f.eks. multisystematrofi eller langtkommet Parkinsons sykdom). Nattlig hypertensjon er vanlig hos pasienter med nevrogen ortostatisk hypotensjon $(10,11)$. Blodtrykket er normalt $10-20 \%$ lavere om natten enn om dagen. Årsaken til nattlig hypertensjon er ikke kjent. Uttalt sympatonevral aktivering av autonom restfunksjon og manglende nattlig tilpasning er én mulig forklaring på dette. En innvending er at også pasienter med svært uttalt affeksjon av perifere autonome nervefibre har uttalt nattlig hypertensjon $(11,16)$. Etter at vår pasient hadde hevet sengens hodeende, kunne han slutte med blodtrykksmedisiner, og symptomene som følge av ortostatisk hypotensjon ble betydelig redusert. En mulig forklaring er at heving av hodeenden ikke bare motvirker den nattlige hypertensjonen, men kanskje også øker karsengens toleranse om dagen.

Hos pasienter med kombinasjonen hypertensjon og ortostatisk hypotensjon bør man mistenke svikt i det autonome nervesystemet. Omvendt bør det undersøkes om pasienter med svikt i det autonome nervesystemet har nattlig hypertensjon. Ved samtidig parkinsonisme er diagnosen multisystematrofi nærliggende. Man kan med enkle tiltak gjøre mye for å lette pasientenes symptomer og plager.

Pasienten har gitt samtykke til at artikkelen blir publisert.

Vi takker Espen Dietrichs og Till Schellhorn for verdifulle innspill.

\section{Kristian Bernhard Nilsen (f. 1974)}

er ph.d., førsteamanuensis ved Norges teknisknaturvitenskapelige universitet og lege i spesialisering innen klinisk nevrofysiologi ved Oslo universitetssykehus, Ullevål.

Forfatter har fylt ut ICMJE-skjemaet og oppgir ingen interessekonflikter.

\section{Pål Berg-Hansen (f. 1972)}

er spesialist i nevrologi og overlege ved Nevrolo gisk avdeling, Oslo universitetssykehus, Ullevål. Forfatter har fylt ut ICMJE-skjemaet og oppgir ingen interessekonflikter.

\section{Eivind Berge (f. 1964)}

er dr.med. og overlege ved Kardiologisk avdeling, Oslo universitetssykehus, Ullevål

Forfatter har fylt ut ICMJE-skjemaet og oppgir ingen interessekonflikter.

\section{Mette Ajer Petterson (f. 1951)}

er fastlege ved Abilds $\varnothing$ legekontor i Oslo. Forfatter har fylt ut ICMJE-skjemaet og oppgir ingen interessekonflikter.

\section{Knut Gjesdal (f. 1944)}

er professor dr.med. ved Kardiologisk avdeling, Oslo universitetssykehus, Ullevål.

Forfatter har fylt ut ICMJE-skjemaet og oppgir ingen interessekonflikter.

\section{Litteratur}

1. Robertson D. The pathophysiology and diagnosis of orthostatic hypotension. Clin Auton Res 2008. 18 (suppl 1): $2-7$

2. Freeman R, Wieling W, Axelrod FB et al. Consensus statement on the definition of orthostatic hypotension, neurally mediated syncope and the postural tachycardia syndrome. Clin Auton Res 2011; 21: 69-72.

3. Fiqueroa JJ, Basford JR, Low PA. Preventing and treating orthostatic hypotension: As easy as A, B C. Cleve Clin J Med 2010; 77: 298-306.

4. Moya A, Sutton R, Ammirati F et al. Guidelines for the diagnosis and management of syncope (version 2009). Eur Heart J 2009: 30: 2631 - 71.

5. Grendahl H, Gjesdal K. Den praktiske nytten av ambulant langtids EKG-registrering. Tidsskr Nor Lægeforen 1993; 113: 839-41.

6. Tysnes OB, Vilming ST. Atypisk parkinsonisme. Tidsskr Nor Legeforen 2008; 128: 2077-80.

7. Toft M, Aasly J. Genetikk ved Parkinsons sykdom. Tidsskr Nor Lægeforen 2004; 124: 922-4.

8. Stefanova N, Bücke P, Duerr S et al. Multiple system atrophy: an update. Lancet Neurol 2009 8: $1172-8$.

9. Thomaides T, Bleasdale-Barr K Chaudhuri KR et al. Cardiovascular and hormonal responses to liquid food challenge in idiopathic Parkinson's disease, multiple system atrophy, and pure autonomic failure. Neurology 1993: 43: $900-4$

10. Mann S, Altman DG, Raftery EB et al. Circadian variation of blood pressure in autonomic failure Circulation 1983; 68: 477-83.

11. Goldstein DS, Pechnik S, Holmes C et al. Association between supine hypertension and orthostatic hypotension in autonomic failure. Hypertension 2003; 42: 136-42

12. Gilman S, Wenning GK, Low PA et al. Second con sensus statement on the diagnosis of multiple system atrophy. Neurology 2008; 71: 670-6

13. Luciano GL, Brennan MJ, Rothberg MB. Postprandial hypotension. Am J Med 2010; 123: 281.e1-6.

14. Riley DE. Orthostatic Hypotension in Multiple System Atrophy. Curr Treat Options Neurol 2000 2: $225-30$

15. Low PA, Gilden JL, Freeman R et al. Efficacy of midodrine vs placebo in neurogenic orthostatic hypotension. A randomized, double-blind multicenter study. JAMA 1997; 277: 1046-51.

16. Okamoto LE, Gamboa A, Shibao C et al. Nocturnal blood pressure dipping in the hypertension of autonomic failure. Hypertension 2009; 53: 363-9.

Mottatt 30.11.2011, første revisjon innsendt 20.2. 2012, godkjent 29.03. 2012. Medisinsk redaktør Merete Kile Holtermann. 